\title{
Predictors of Short-term Outcome in Chinese Patients with Ambulatory Heart Failure for Heart Transplantation with Ejection Fraction $<25 \%$
}

\author{
Chien-Ming HuAng, MD, Mason-Shing Young, ${ }^{1} \mathrm{MD}$, \\ and Jeng $\mathrm{WEI},{ }^{2} \mathrm{PhD}$
}

\begin{abstract}
SUMMARY
Heart transplantation (HT) provides longer survival than that of the natural history in patients with dilated cardiomyopathy (DCM). However, the optimal timing for cardiac transplantation and predictors of mortality in patients with end-stage cardiomyopathy (ESCM) has been poorly defined. The primary purpose of this study focused on the natural history of ambulatory patients with ESCM for HT assessment. Secondly, we tried to determine prognostic factors of individuals with the poorest short-term outcome and the optimal timing for HT in patients with ESCM. Finally, clinical treatment with angiotensin converting-enzyme inhibitors (ACEIs), carvedilol and amiodarone in the prevention of mortality caused by ESCM, were retrospectively evaluated.
\end{abstract}

The short-term outcomes of 119 referral patients with ESCM for four years were observed. The patients had New York Heart Association class III to IV dyspnea at initial assessment for HT. Left ventricular ejection fraction (LVEF) was $17 \pm 6 \%$ and cardiac index (CI) was $2.0 \pm 0.6 \mathrm{l} / \mathrm{min} / \mathrm{m}^{2}$. After optimization of medical treatment, the patients were divided into two major groups according to CI equal to or less than $2.0 \mathrm{l} / \mathrm{min} / \mathrm{m}^{2}$ and more than $2.0 \mathrm{l} / \mathrm{min} / \mathrm{m}^{2}$. HTs were accepted in 88 patients and the patients were divided into two groups: medical treatment (group 1, 56 patients) or HT (group 3, 32 patients); HT was not accepted in the other 31 patients (group 2). We studied the probability of the survival curve and prognostic variables of the groups with medical treatment in the follow-up of $12 \pm 9$ months.

During follow-up, 49 patients were alive without HT. The remaining 38 patients died; 27 patients were in group 1 and 11 patients were in group 2. Eight deaths in group 2 were sudden. The actuarial survival rate among the non-HT population was $73 \%, 68 \%$, $63 \%$, and $56 \%$ at 3, 6, 9 and 12 months, respectively. The actuarial survival rate among group 1 was $70 \%, 59 \%, 55 \%$, and $52 \%$ at 3, 6, 9 and 12 months, respectively. The actuarial survival rate among group 2 was $87 \%, 85 \%, 77 \%$, and $65 \%$ at 3,6, 9 and 12 months, respectively. A comparison, excluding patients with HT, was performed with those who had survived $<1$ year and $\geq 1$ year after assessment, and those who had died. Two parameters were independent predictors of prognosis on univariate and multivariate analysis: total pulmonary vascular resistance (TPR) $\geq 14$ Wood units (W) and CI $<1.65$

From the Division of Cardiology, Department of Medicine, ${ }^{1}$ Department of Medicine, ${ }^{2}$ Department of Cardiovascular Surgery, Cheng-Hsin Rehabilitation Center, Taipei, Taiwan, Republic of China.

Address for correspordence: Chin-Ming Huang, MD, Division of Cardiology, Department of Internal Medicine, Cheng-Hsin Hospital, No. 45, Cheng-Hsin Street, Peitou 112, Taipei, Taiwan, Republic of China.

Received for publication January 4, 2000

Revised and accepted February 28, 2000. 
$l / \mathrm{min} / \mathrm{m}^{2}$ at 6 and 12 months after assessment. Treatment with amiodarone for ventricular tachycardia (VT) showed no convincing role in the prevention of sudden death in our patients. Also, treatment with ACEIs or carvedilol for heart failure was unconvincing to improve the short-term outcome in this study.

Our results suggest in properly selected patients that HT should be considered within six months among patients with severe heart failure. Hemodynamic parameters associated with right cardiac function are important determinants of mortality caused by progressive heart failure. Predictors such as CI and TPR may be considered as important markers of mortality in prediction of short-term outcome in patients with ESCM, as other predictors reported in the literature. (Jpn Heart J 2000; 41: 349-369)

Key words: Heart failure, Cardiomyopathy, Heart transplantation, Chinese patients

PATIENTS with advanced cardiac failure have a poor outcome. ${ }^{1)}$ These patients usually develop progressive deterioration of hemodynamics and symptoms leading to death even with intensive medical treatment and / or mechanical support. Sudden cardiac death can occur in patients without severe symptoms of heart failure. Moreover, it is important to know that the clinical condition of a small number of patients may improve while they are on the waiting list, ${ }^{2)}$ and that an observation period before HT is necessary. Several potential prognostic markers, including gender, age, sex, etiology, EF, PWP, peak exercise oxygen capacity (PEOC), levels of plasma norepinephrine (NE) and atrial natriuretic factor (ANF), have been widely reported in patients with severe cardiac failure in the Western world. ${ }^{3-10)}$ However, the predictors of outcome varied from study to study. Up to now, there is still no consensus regarding the most powerful markers for predicting mortality and an optimal timing for HT. In addition, the survival rate of potential candidates may decrease, especially regarding the waiting time, an increasing number of candidates and a shortage of heart donors. ${ }^{11,12)}$ It is possible that HT might be performed too early in some patients who were not really indicated, if the reason for the HT was merely because of an available donor. Therefore, it is crucial to determine the prognostic predictors, priority, and optimal timing for HT among patients with severe cardiac failure. The primary purpose of this study focused on the natural history of patients with ESCM for HT assessment. Secondly, we tried to determine prognostic factors of individuals with the poorest short-term outcome and the optimal timing for HT in patients with ESCM. Finally, clinical treatment with ACEIs and amiodarone in the prevention of mortality caused by ESCM, were retrospectively evaluated. On the basis of clinical, echocardiographic and hemodynamic data to predict mortality in patients with end-stage heart failure, we have studied 119 such patients for more than four years. 


\section{METHODS}

The study group comprised 119 consecutive patients (91 men, 28 women; mean age $49 \pm 14$ years; range 9 to 65) with end-stage heart failure due to ischemic or non-ischemic dilated cardiomyopathy who were referred to Cheng-Hsin Rehabilitation Center for assessment for HT from May 1995 to September 1999. The mean interval from the onset of symptoms of cardiac failure (New York Heart Association class III-IV dyspnea) to our initial assessment was $28 \pm 32$ months. The mean LVEF was $17 \pm 6 \%( \pm \mathrm{SD})($ range $4 \%$ to $24 \%)$. Mean time of follow-up was $12 \pm 9$ months (range 0.1 to 36); death and HT were considered endpoints for follow-up. All patients underwent 2-D, M-mode and color echocardiography and cardiac catheterization after rigorous tailored therapy with or without inotropic agents. The averaged timing of M-mode, two-dimensional and color echocardiography and cardiac catheterization after intensive medical treatment for heart failure were $7 \pm 5$ and $12 \pm 5$ days, respectively.

Study design: All patients with ESCM in the study were referred to our institutions for HT. If refractory heart failure persisted after optimization of medical therapy, the patient was evaluated for HT.

At assessment, all patients were receiving furosemide at a mean daily dose of $64 \pm 35 \mathrm{mg} /$ day, $89 \%$ were taking ACEIs, and $82 \%$ were taking digitalis. Intravenous inotropic drugs (dopamine, dobutamine and isoproterenol) were needed by $75 \%$ of the patients; $52 \%$ of the patients needed more than one inotropic drug.

Inclusion criteria: All patients had dilated cardiomyopathy on the basis of four presentations: (1) symptoms and signs of left or biventricular failure, (2) refractory heart failure persisted after optimization of medical treatment, (3) global left ventricular hypokinesis with prominent left ventricular dilatation on echocardiography, and (4) angiographic or radionuclide ventriculography and / or echocardiography revealed LVEF $<25 \%$.

Exclusion criteria: Patients with one of the following contraindications for HT were excluded from our study: old age (> $65 \mathrm{yr}$ ), acute myocarditis proved by endomyocardial biopsy, reversible and operable myocardial ischemia proved by positron emission tomography (PET), active infection, irreversibly high pulmonary vascular resistance ( $\geq 6$ Wood units after vasodilator therapy), irreversible renal dysfunction, severe cerebrovascular and peripheral vascular occlusive disease, severe chronic obstructive airway disease, coexisting systemic disease with poor prognosis, active peptic ulcer, poor medical compliance and psychosocial problems or drug 
addiction, positive serologic findings for human immunodeficiency virus, or positive toxoplasmosis immunoglobulin $\mathrm{M}$ antibody.

HT protocol for treatment of severe heart failure: Our final decision concerning HTs for potential candidates was based on the following features: (1) $\mathrm{LVEF} \leq 20 \%, \mathrm{CI} \leq 2.0 \mathrm{l} / \mathrm{min} / \mathrm{m}^{2}$, and $/$ or $\mathrm{PEOC} \leq 14 \mathrm{ml} / \mathrm{kg} / \mathrm{min}$, (2) refractory deterioration of hemodynamics and severely limited symptoms (symptomatic fluid retention, clinical evidence of low cardiac output with hypoperfusion) after optimization of medical treatment, and (3) availability of heart donors for candidates (on the waiting list) who were expected to die within 12 months on the basis of severely limiting symptoms.

Cardiac catheterization: Right- and left-sided cardiac catheterization were performed in all patients on medical treatment. Right- and left-sided heart pressures were measured before angiography through a 7 or 6 French catheter placed in the cardiac chambers by a femoral or radial approach combined with a jugular technique. ${ }^{13)}$ Cardiac output was determined by the Fick method and then the cardiac index derived.

Endomyocardial biopsy: Endomyocardial biopsy was performed in all patients with nonischemic cardiomyopathy to exclude myocarditis or specific heart muscle disease. At least three samples were taken from the right ventricle in each patient.

M-mode, two-dimensional and color echocardiography: All study patients underwent M-mode, two-dimensional and color echocardiography. In the Mmode study (oriented in two-dimensional parasternal long-axis and shortaxis view), conventional variables were measured; left ventricular enddiastolic and end-systolic diameters (LVEDD, LVESD), fractional shortening (FS), and end-diastolic thickness of the posterior wall and interventricular septum, end-diastolic diameter of the left atrium (LAD). Chamber diameters were normalized for body surface area. In the color echocardiographic study, the severity of mitral, tricuspid, aortic, and pulmonary regurgitation was semiquantitatively assessed as grade $1+$ to $4+$.

Patients were divided into two groups according to LVEF and CI. The patients had New York Heart Association class III to IV dyspnea at initial assessment for HT. HT was considered indicated in 88 patients $(\mathrm{EF}<25$ $\%$ and $\mathrm{CI} \leq 2.0 \mathrm{l} / \mathrm{min} / \mathrm{m}^{2}$ ). These patients were divided into two groups: a medical treatment group (group 1, 56 patients) and an HT group (group 3, 32 patients). HT was not advised in 31 patients (group 2, EF $<25 \%$ and $\mathrm{CI} \geq 2.0$ liters $/ \mathrm{min} / \mathrm{m}^{2}$ ).

Mode of death was classified according to Hinkle, et al. ${ }^{14)}$ Death due to congestive heart failure was defined as progressive cardiac pump dysfunction with time elapsing before the ultimate cessation of pulse and res- 
piration. Sudden death was defined as an abrupt disorder of the cardiac rhythm in a patient without prior circulatory collapse over the previous two weeks.

Analysis of follow-up data: End points for follow-up were death, HT or the end of the study. The main clinical, hemodynamic and color echocardiographic variables were prospectively recorded in all patients (Tables I and II). Univariate and multivariate comparisons of these variables were performed between patients who were alive without HT at the end of followup (September 1999) and survived $\geq 1$ year after assessment, and those who died during follow-up. Continuous data are expressed as the mean value \pm SD. Differences in variances between group means were compared by unpaired $t$ testing. Differences among patient groups were compared by analysis of variance or chi-square analysis. Actuarial survival curves were constructed for parameters using the Kaplan-Meier product limit survival method with log-rank testing to examine the difference between curves. Cox multivariate regression was used to identify parameters predicting survival. Differences were considered significant for $p$ values $<0.05$. For the purpose of analysis, those patients undergoing HT were considered as lost to follow-up at the date of transplant. To ensure that the inclusion of transplanted patients did not influence our results, each parameter was analyzed with and without these patients included to alert us to any bias that may have been introduced. To ensure that the natural history in patients with ischemic cardiomyopathy did not influence our results, each parameter and actual survival rate was compared with that of the patients with nonischemic cardiomyopathy to alert us to any difference that may have been introduced. The main clinical features, hemodynamics and M-mode, two-dimensional and color echocardiographic data of all patients are listed in Tables I and II. 
Table I. Clinical, Echocardiographic and Hemodynamic Features of 119 Patients Assessed for Heart Transplantation

\begin{tabular}{|c|c|c|c|c|}
\hline & $\begin{array}{l}\text { All Patients } \\
\quad(n=119)\end{array}$ & $\begin{array}{l}\text { Group 1 } \\
(n=56)\end{array}$ & $\begin{array}{l}\text { Group } 2 \\
(n=31)\end{array}$ & $\begin{array}{l}\text { Group } 3 \\
(n=32)\end{array}$ \\
\hline \multicolumn{5}{|l|}{ Clinical data } \\
\hline Age (years) & $49 \pm 14$ & $46 \pm 13$ & $52 \pm 14$ & $52 \pm 12$ \\
\hline Ischemic dilated cardiomyopathy & $18(15 \%)$ & $7(13 \%)$ & $8(26 \%)$ & $3(9 \%)$ \\
\hline Nonischemic dilated cardiomyopathy & $91(85 \%)$ & $49(87 \%)$ & $23(74 \%)$ & $29(91 \%)$ \\
\hline $\operatorname{BSA}\left(\mathrm{m}^{2}\right)$ & $1.7 \pm 0.2$ & $1.7 \pm 0.2$ & $1.7 \pm 0.2$ & $1.6 \pm 0.2$ \\
\hline $\mathrm{BP}(\mathrm{mm} \mathrm{Hg})$ & $110 \pm 21$ & $108 \pm 22$ & $118 \pm 22$ & $108 \pm 14$ \\
\hline Symptom history (months)* & $28 \pm 32$ & $27 \pm 29$ & $28 \pm 34$ & $31 \pm 34$ \\
\hline NYHA functional class & $3.2 \pm 0.3$ & $3.3 \pm 0.3$ & $3.1 \pm 0.4$ & $3.3 \pm 0.4$ \\
\hline $\operatorname{LVEF}(\%)$ & $17 \pm 6$ & $16 \pm 5$ & $17 \pm 6$ & $17 \pm 6$ \\
\hline Heart rate (beats per min.) & $94 \pm 16$ & $96 \pm 19$ & $93 \pm 13$ & $93 \pm 15$ \\
\hline Atrial fibrillation & $24(20 \%)$ & $16(29 \%)$ & $4(13 \%)$ & $4(13 \%)$ \\
\hline Ventricular tachycardia & $80(67 \%)$ & $39(70 \%)$ & $16(52 \%)$ & $25(78 \%)$ \\
\hline Cordarone & $70(59 \%)$ & $39(52 \%)$ & $13(42 \%)$ & $18(56 \%)$ \\
\hline LBBB & $27(23 \%)$ & $14(25 \%)$ & $6(19 \%)$ & $7(23 \%)$ \\
\hline Inotropic agents & $87(73 \%)$ & $41(73 \%)$ & $18(58 \%)$ & $29(90 \%)$ \\
\hline \multicolumn{5}{|l|}{ Echocardiographic data } \\
\hline LVEDD (mm) & $70 \pm 9$ & $70 \pm 9$ & $69 \pm 9$ & $72 \pm 10$ \\
\hline $\operatorname{LVESD}(\mathrm{mm})$ & $61 \pm 10$ & $60 \pm 9$ & $61 \pm 10$ & $63 \pm 10$ \\
\hline LVEDDI $\left(\mathrm{mm} / \mathrm{m}^{2}\right)$ & $42 \pm 6$ & $42 \pm 6$ & $40 \pm 6$ & $45 \pm 8$ \\
\hline LVESDI $\left(\mathrm{mm} / \mathrm{m}^{2}\right)$ & $37 \pm 7$ & $36 \pm 6$ & $35 \pm 7$ & $39 \pm 7 *$ \\
\hline FS $(\%)$ & $13 \pm 6$ & $14 \pm 7$ & $13 \pm 6$ & $13 \pm 6$ \\
\hline MR (0-4) & $2 \pm 1$ & $2 \pm 1$ & $2 \pm 1$ & $2 \pm 1$ \\
\hline \multicolumn{5}{|l|}{ Hemodynamic data } \\
\hline $\mathrm{MBP}(\mathrm{mm} \mathrm{Hg})$ & $90 \pm 15$ & $89 \pm 18$ & $93 \pm 13$ & $89 \pm 12$ \\
\hline SPAP (mm Hg) & $53 \pm 16$ & $55 \pm 15$ & $41 \pm 13^{*}$ & $61 \pm 16$ \\
\hline MPAP (mm Hg) & $38 \pm 12$ & $39 \pm 11$ & $30 \pm 9 *$ & $43 \pm 11$ \\
\hline PCWP (mm Hg) & $26 \pm 10$ & $28 \pm 10$ & $19 \pm 8^{*}$ & $30 \pm 9$ \\
\hline $\mathrm{RAP}(\mathrm{mm} \mathrm{Hg})$ & $13 \pm 8$ & $15 \pm 8$ & $7 \pm 6^{*}$ & $15 \pm 8$ \\
\hline PVR (Wood Units) & $4.1 \pm 2.8$ & $4 \pm 3$ & $2 \pm 1^{*}$ & $5 \pm 3$ \\
\hline TPR (Wood Units) & $13 \pm 6$ & $15 \pm 6$ & $6 \pm 2 *$ & $17 \pm 7$ \\
\hline SVR (Wood Units) & $25 \pm 8$ & $25 \pm 7$ & $18 \pm 4^{*}$ & $29 \pm 8$ \\
\hline $\mathrm{CI}\left(l / \mathrm{min} / \mathrm{m}^{2}\right)$ & $2.0 \pm 0.6$ & $1.7 \pm 0.3$ & $2.9 \pm 0.5^{*}$ & $1.7 \pm 0.3$ \\
\hline
\end{tabular}

Values presented are mean \pm SD or number $(\%)$ of patients. ACEI $=$ angiotensin-converting enzyme inhibitor; LBBB = left ventricular bundle branch block; LVEF = left ventricular ejection fraction; LVEDD $=$ left ventricular end-diastolic diameter; LVEDI = left ventricular end-diastolic index; LVESD = left ventricular end-diastolic diameter; LVESDI = left ventricular end-diastolic diameter index; MBP = mean blood pressure; SPAP = systolic pulmonary artery pressure; $\mathrm{PWP}=$ pulmonary artery wedge pressure; RAP = right atrial pressure; PVR = pulmonary vascular resistance; $\mathrm{TPR}=$ total pulmonary vascular resistance; $\mathrm{SVR}=$ systemic vascular resistance $; \mathrm{CI}=$ cardiac index $; \mathrm{FS}=$ fractional shortening; $\mathrm{MR}=$ mitral regurgitation; * interval from onset of heart disease; NYHA = New York Heart Association. $* p<0.05$ group 1versus group 2 . $* * p<0.05$ group 1versus group 3 . 
Table II. Comparison of Clinical, Echocardiographic and Hemodynamic Features of 87 Non-transplanted Patients with Ischemic and Nonischemic Dilated Cardiomyopathy Assessed for Heart Transplantation

\begin{tabular}{|c|c|c|c|}
\hline & $\begin{array}{c}\text { Ischemic CM } \\
\quad(n=15)\end{array}$ & $\begin{array}{c}\text { Non-ischemic CM } \\
\quad(n=72)\end{array}$ & $p$ value \\
\hline \multicolumn{4}{|l|}{ Clinical data } \\
\hline Age (years) & $54 \pm 10$ & $49 \pm 14$ & NS \\
\hline $\operatorname{BSA}\left(\mathrm{m}^{2}\right)$ & $1.7 \pm 0.2$ & $1.7 \pm 0.2$ & NS \\
\hline $\mathrm{BP}(\mathrm{mm} \mathrm{Hg})$ & $115 \pm 24$ & $110 \pm 22$ & NS \\
\hline Symptom history (months)* & $41 \pm 34$ & $24 \pm 29$ & NS \\
\hline NYHA functional class & $3.2 \pm 0.3$ & $3.3 \pm 0.3$ & NS \\
\hline $\operatorname{LVEF}(\%)$ & $18 \pm 5$ & $16 \pm 5$ & NS \\
\hline Heart rate (beats per min.) & $89 \pm 12$ & $96 \pm 18$ & NS \\
\hline Atrial fibrillation & $3(21 \%)$ & $15(21 \%)$ & NS \\
\hline Ventricular tachycardia & $10(67 \%)$ & $45(63 \%)$ & NS \\
\hline Cordarone & $7(47 \%)$ & $35(49 \%)$ & NS \\
\hline Carvedilol & $3(20 \%)$ & $11(15 \%)$ & NS \\
\hline Inotropic agents & $11(73 \%)$ & $49(68 \%)$ & NS \\
\hline \multicolumn{4}{|l|}{ Echocardiographic data } \\
\hline LVEDD (mm) & $70 \pm 9$ & $70 \pm 9$ & NS \\
\hline $\operatorname{LVESD}(\mathrm{mm})$ & $60 \pm 10$ & $60 \pm 9$ & NS \\
\hline FS $(\%)$ & $13 \pm 5$ & $14 \pm 7$ & NS \\
\hline $\mathrm{MR}(0-4)$ & $2 \pm 1$ & $2 \pm 1$ & NS \\
\hline \multicolumn{4}{|l|}{ Hemodynamic data } \\
\hline $\mathrm{MBP}(\mathrm{mm} \mathrm{Hg})$ & $90 \pm 15$ & $90 \pm 17$ & NS \\
\hline SPAP (mm Hg) & $51 \pm 16$ & $55 \pm 16$ & NS \\
\hline MPAP $(\mathrm{mm} \mathrm{Hg})$ & $34 \pm 11$ & $36 \pm 11$ & NS \\
\hline PCWP (mm Hg) & $22 \pm 9$ & $25 \pm 10$ & NS \\
\hline RAP (mm Hg) & $11 \pm 6$ & $12 \pm 8$ & NS \\
\hline PVR (Wood Units) & $3 \pm 2$ & $4 \pm 3$ & NS \\
\hline TPR (Wood Units) & $9 \pm 5$ & $12 \pm 7$ & NS \\
\hline SVR (Wood Units) & $22 \pm 7$ & $22 \pm 7$ & NS \\
\hline $\mathrm{CI}\left(l / \mathrm{min} / \mathrm{m}^{2}\right)$ & $2.2 \pm 0.5$ & $2.1 \pm 0.7$ & NS \\
\hline
\end{tabular}

Abbreviations as in Table $1 . \mathrm{CM}=$ cardiomyopathy.

\section{RESUltS}

Initial assessment and general outcome: The main clinical, hemodynamic and color echocardiographic data are listed in Tables I and II. Of 119 patients, HT was considered indicated in $88(74 \%)$ patients; the remaining $31(26 \%)$ patients were not accepted (e.g. CI > $2.0 l / \mathrm{min} / \mathrm{m}^{2}$ ) for HT after initial assessment. HT was performed in $32(27 \%)$ patients and 49 (41\%) patients were alive without HT at the end of follow-up. The remaining $38(32 \%)$ patients died; 27 (48\%) patients were in group 1 and $11(35 \%)$ patients were in group 2 (Tables I and IV). Improved left ven- 
tricular function was also observed in three patients after serial follow-up: one in group 1 and two in group 2.

Our data showed no significant statistical differences in any of the analyzed variables (Table II) or actual survival rates (Figure 1) in our nontransplanted ischemic and nonischemic cardiomyopathy patients. Therefore, all data from all patients were analyzed together.

Causes of death: In group 1, the causes of death were sudden death in 4 $(15 \%)$, progressive heart failure in $21(78 \%)$, pulmonary emboli in 1 (4\%) and septic shock in $1(4 \%)$ patient. In group 2, they were sudden death in $8(73 \%)$, progressive heart failure in $2(18 \%)$ and septic shock in $1(9 \%)$ patient. Sudden death appeared to increase significantly $(p<$ 0.05 ) in patients who were not accepted for HT after initial assessment. By contrast, the majority of deaths in group 1 resulted from progressive heart failure $(p<0.005)$. The results are listed in Table III. On the other hand, sudden death $(p=0.37)$ and progressive heart failure $(p=0.47)$ showed no statistically significant difference between patients with ischemic and nonischemic cardiomyopathy in our study.

Whole group survival: The short-term outcomes of the remaining 29 nontransplant patients in group 1 and 20 patients in group 2 were benign. The $3,6,9$ and 12 month actuarial survival rates among non-transplant populations were $73 \%, 68 \%, 63 \%$, and $56 \%$, respectively. The 3, 6, 9 and 12 month actuarial survival rates of patients in group 1 were $70 \%, 59 \%$, $55 \%$, and $52 \%$, respectively. The 3, 6, 9 and 12 month actuarial survival

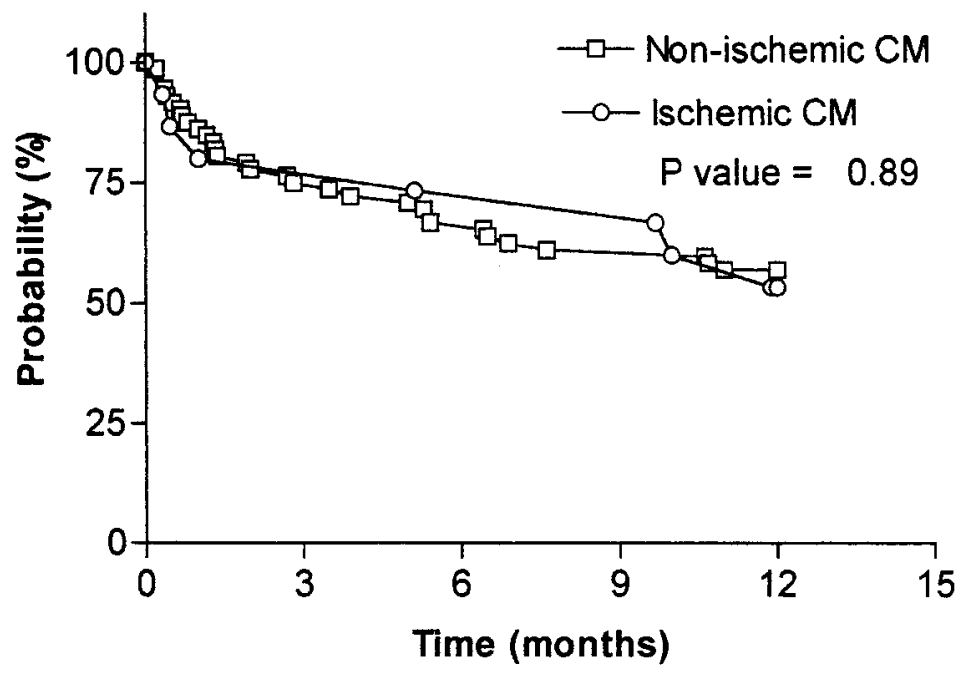

Figure 1. Kaplan-Meier survival curves in 87 patients with a left ventricular ejection fraction $<25 \%$ and subdivided groups with ischemic and non-ischemic cardiomyopathy at one-year after assessment. 


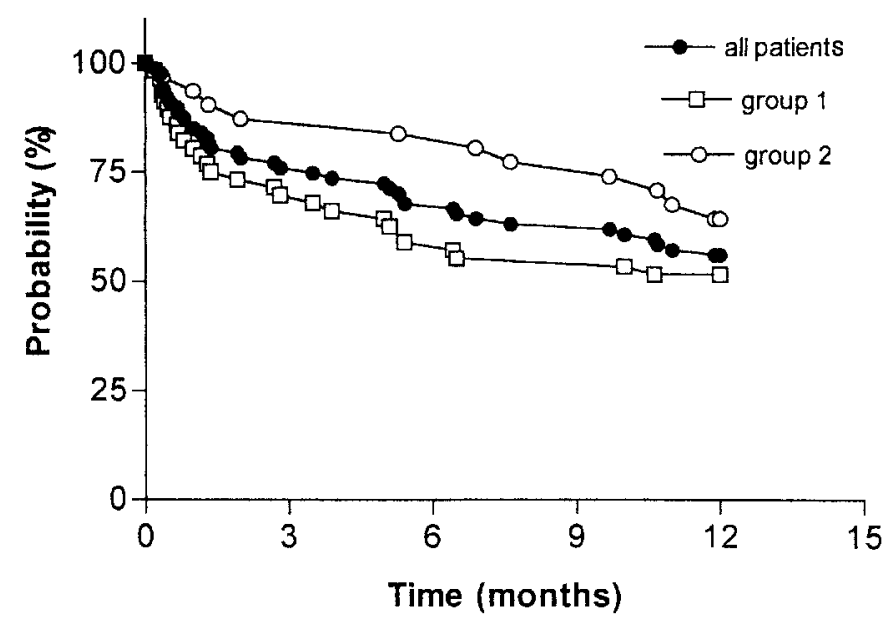

Figure 2. Kaplan-Meier survival curves in 87 patients with a left ventricular ejection fraction $<25 \%$ and subdivided groups of cardiac index $\leq 2.0$ and $>2.0$ liters $/ \mathrm{min} / \mathrm{m}^{2}$ at one-year after assessment.

Table III. Comparison of Survivors and Nonsurvivors in Groups 1 and 2

\begin{tabular}{|c|c|c|c|c|}
\hline & \multicolumn{2}{|c|}{ Group 1} & \multicolumn{2}{|c|}{ Group 2} \\
\hline & $\begin{array}{l}\text { Survivors } \\
(n=29)\end{array}$ & $\begin{array}{l}\text { Nonsurvivors } \\
\quad(n=27)\end{array}$ & $\begin{array}{l}\text { Survivors } \\
(n=20)\end{array}$ & $\begin{array}{c}\text { Nonsurvivors } \\
\quad(n=11)\end{array}$ \\
\hline Mean age (years) & $47 \pm 13$ & $45 \pm 14$ & $51 \pm 13$ & $53 \pm 18$ \\
\hline Duration of follow-up (months) & $19 \pm 6$ & $3 \pm 3 * *$ & $19 \pm 6$ & $6 \pm 4 * *$ \\
\hline NYHA functional class & $3.2 \pm 0.3$ & $3.3 \pm 0.3$ & $3.1 \pm 0.3$ & $3.2 \pm 0.5$ \\
\hline $\operatorname{LVEF}(\%)$ & $16 \pm 5$ & $15 \pm 6$ & $17 \pm 6$ & $18 \pm 4$ \\
\hline Peak exercise oxygen capacity $(\mathrm{m} / / \mathrm{kg} / \mathrm{min})$ & $14 \pm 4$ & $12 \pm 3$ & $14 \pm 3$ & $14 \pm 7$ \\
\hline Heart rate (beats per min.) & $92 \pm 16$ & $100 \pm 21$ & $93 \pm 13$ & $93 \pm 18$ \\
\hline Ventricular tachycardia (VT) & $19(66 \%)$ & $20(74 \%)$ & $9(45 \%)$ & $7(64 \%)$ \\
\hline Cordarone & $16(55 \%)$ & $13(48 \%)$ & $6(30 \%)$ & $7(64 \%)$ \\
\hline Inotropic agents & $60 \%$ & $90 \% *$ & $50 \%$ & $72 \%$ \\
\hline $\operatorname{LVEDI}\left(\mathrm{mm} / \mathrm{m}^{2}\right)$ & $41 \pm 6$ & $43 \pm 5$ & $40 \pm 5$ & $41 \pm 6$ \\
\hline LVESI (mm per $\mathrm{m}^{2}$ ) & $35 \pm 6$ & $38 \pm 6$ & $34 \pm 6$ & $36 \pm 8$ \\
\hline FS $(\%)$ & $15 \pm 6$ & $13 \pm 8$ & $14 \pm 5$ & $12 \pm 6$ \\
\hline $\mathrm{BP}(\mathrm{mm} \mathrm{Hg})$ & $112 \pm 23$ & $103 \pm 21$ & $121 \pm 23$ & $112 \pm 21$ \\
\hline $\operatorname{MBP}(\mathrm{mm} \mathrm{Hg})$ & $93 \pm 18$ & $85 \pm 18$ & $95 \pm 13$ & $88 \pm 13$ \\
\hline SPAP (mm Hg) & $53 \pm 16$ & $58 \pm 14$ & $41 \pm 13$ & $42 \pm 13$ \\
\hline MPAP (mm Hg) & $38 \pm 12$ & $42 \pm 10$ & $30 \pm 9$ & $30 \pm 7$ \\
\hline PWP $(\mathrm{mm} \mathrm{Hg})$ & $25 \pm 9$ & $30 \pm 9 *$ & $18 \pm 8$ & $20 \pm 9$ \\
\hline RAP (mm Hg) & $13 \pm 8$ & $17 \pm 6$ & $7 \pm 5$ & $8 \pm 7$ \\
\hline PVR (Wood Units) & $4 \pm 2$ & $5 \pm 3$ & $2 \pm 1$ & $2 \pm 1$ \\
\hline TPR (Wood Units) & $12 \pm 4$ & $17 \pm 7 * *$ & $6 \pm 3$ & $7 \pm 2$ \\
\hline SVR (Wood Units) & $25 \pm 6$ & $26 \pm 8$ & $17 \pm 4$ & $18 \pm 4$ \\
\hline $\mathrm{CI}\left(l / \mathrm{min} / \mathrm{m}^{2}\right)$ & $1.8 \pm 0.3$ & $1.6 \pm 0.3 *$ & $3.0 \pm 0.6$ & $2.7 \pm 0.4$ \\
\hline
\end{tabular}

Abbreviations as in Table 1. $\left({ }^{*} p<0.05 ; * * p<0.005\right)$ 
rates of patients in group 2 were $87 \%, 85 \%, 77 \%$, and $65 \%$. The results are shown in Figure 2. The 3, 6 and 9 month actuarial survival rates showed significant statistical differences between groups 1 and 2 $(p<0.05)$. Although there was no significant statistical difference for 1 year survival between groups 1 and 2 at the end of follow-up, sudden death appeared to increase significantly $(p<0.05)$ in patients who were considered not accepted for HT after initial assessment (Table IV). By contrast, the majority of deaths of patients in group 1 resulted from progressive heart failure $(p<0.005)$ and the patients died within six months after initial assessment. Clinical characteristics of the nonsurvivors are summarized in Table IV.

Univariate and multivariate analyses: Univariate comparison of all patients in groups 1 and 2 showed significant differences in CI, TPR, PWP, pulmonary artery pressure (PAP), right atrial pressure (RAP), systemic vascular resistance (SVR), and pulmonary vascular resistance (PVR) (Table I). However, there were no significant statistical differences in EF, FS, mitral regurgitation (MR), left ventricular end-diastolic index (LVEDI), left ventricular end-systolic diameter index (LVESI) or other clinical variables.

Table IV. Univariate Comparison of Nonsurvivors and Mode of Death

\begin{tabular}{lccc}
\hline & Group 1 & Group 2 & $p$ value \\
\hline Deaths (n) & 27 & 11 & \\
Age (years) & $45 \pm 14$ & $53 \pm 18$ & $\mathrm{NS}$ \\
Sex (n)NS & & & \\
$\quad$ Male & 19 & 8 & \\
Female & 8 & 3 & \\
Etiology (n) & 4 & 3 & $\mathrm{NS}$ \\
$\quad$ Ischemic dilated cardiomyopathy & 23 & 8 & $\mathrm{NS}$ \\
$\quad$ Nonischemic dilated cardiomyopathy & $15 \pm 6$ & $18 \pm 7$ & $\mathrm{NS}$ \\
LVEF (\%) & $12 \pm 3$ & $14 \pm 4$ & $\mathrm{NS}$ \\
Peak exercise oxygen capacity (ml/ kg / min) & $30 \pm 10$ & $20 \pm 9$ & $<0.01$ \\
PWP (mm Hg) & $17 \pm 7$ & $8 \pm 2$ & $<0.0005$ \\
TPR (Wood unit) & $1.6 \pm 0.4$ & $2.7 \pm 0.4$ & $<0.0001$ \\
CI $\left(l /\right.$ min / m ${ }^{2}$ ) & 19 & 7 & $\mathrm{NS}$ \\
Ventricular tachycardia (VT) & 15 & 7 & $\mathrm{NS}$ \\
Cordarone & & & \\
Mode (n) & 21 & 1 & $<0.005$ \\
$\quad$ Congestive heart failure & 4 & 8 & $<0.05$ \\
$\quad$ Sudden death & 2 & 2 & \\
$\quad$ Noncardiac death & $2.9 \pm 3.0$ & $6.2 \pm 4.4$ & $<0.05$ \\
Duration of follow-up (mo) & & &
\end{tabular}

Abbreviations as in Table I. (NS = nonsignificant) 
Univariate comparison of the survivors and nonsurvivors in groups 1 and 2 was performed (Table III). Comparison of the survivors and nonsurvivors of group 1 demonstrated significant differences in CI, TPR, PWP and inotropic agent treatment. There were no significant differences between survivors and nonsurvivors for other analyzed variables in group 1. Also, there were no significant statistical differences for any of the analyzed variables in group 2 .

Univariate comparison among all of the nonsurvivors between groups 1 and 2 are shown in Table IV. The results also showed significant differences in CI, PWP and TPR. Moreover, the duration of survival and mode of mortality were statistically different between the two groups as well. The results of univariate (log rank) and multivariate analyses are tabulated in Tables III to V. By both univariate and multivariate analysis, TPR and CI were the best prognostic predictors (Table IV).

Survival Curves: The 1-year survival curves were derived with subdivisions of TPR, PWP, and CI. Patients were divided into the following TPR: 14 and $17 \mathrm{~W}$ or greater, less than $14 \mathrm{~W}$; CI: less than $1.65 \mathrm{l} / \mathrm{min} /$ $\mathrm{m}^{2}, 1.65 \mathrm{l} / \mathrm{min} / \mathrm{m}^{2}$ or greater; PWP: $28 \mathrm{~mm} \mathrm{Hg}$ or greater, less than 28 $\mathrm{mm} \mathrm{Hg}$. The results are shown in Figures 2 to 4 . At this level, CI, PWP and TPR achieved significance in the univariate analyses. Cumulative survival is depicted in Figures 3 to 5. Patients with $\mathrm{CI}<1.65 \mathrm{l} / \mathrm{min} / \mathrm{m}^{2}$ had a survival rate of $48 \%$, and $42 \%$ of patients with PWP $\geq 28 \mathrm{~mm} \mathrm{Hg}$ had survival rates of $50 \%$ and $42 \%$ at 6 and 12 months, respectively. Patients with a TPR $\geq 14 \mathrm{~W}$ had survival rates of $48 \%$ and $41 \%$, while those with a TPR $\geq 17 \mathrm{~W}$ had survival rates of $27 \%$ and $20 \%$ at 6 and 12 months, respectively.

Significant correlations between the prognostic predictors, including CI and TPR $(r=-0.68, p=0.0001)$, PWP and CI $(r=-0.36, p=0.007)$,

Table V. Multivariate Comparison of Survivors and Nonsurvivors

\begin{tabular}{lclccr}
\hline Predictors & Coefficients & S E & $p$ & Lo95\% & Hi95\% \\
\hline MBP & 0.0075 & 0.1805 & 0.9671 & -0.3445 & 0.3594 \\
LVEDI & -0.0627 & 0.1831 & 0.7321 & -0.4197 & 0.2943 \\
LVESI & -0.074 & 0.1252 & 0.5546 & -0.3181 & 0.1701 \\
PCWP & -0.0005 & 0.0052 & 0.9195 & -0.0107 & 0.0096 \\
TPR & -0.4507 & 0.165 & 0.0063 & -0.7725 & -0.1289 \\
CI & -0.9306 & 0.4041 & 0.0213 & -1.7186 & -0.1426 \\
\hline
\end{tabular}

Abbreviations as in Table I. 


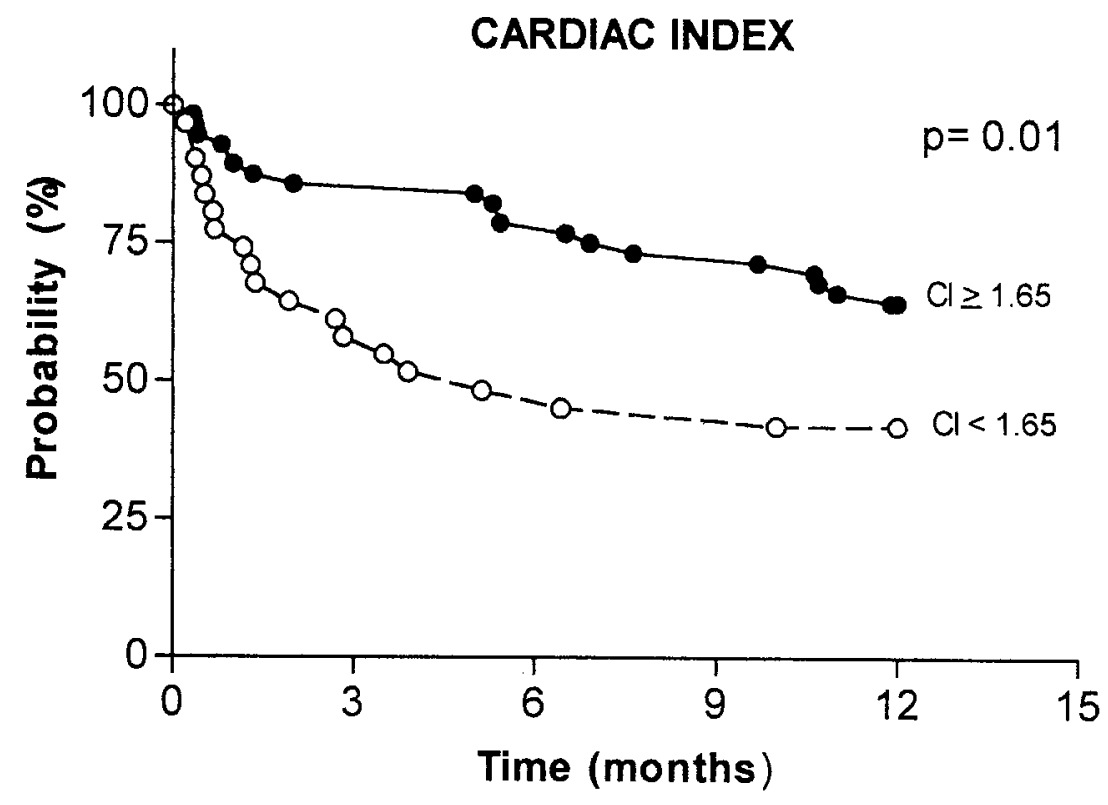

Figure 3. Actuarial survival curves according to cardiac index in liters $/ \mathrm{min} / \mathrm{m}^{2}$.

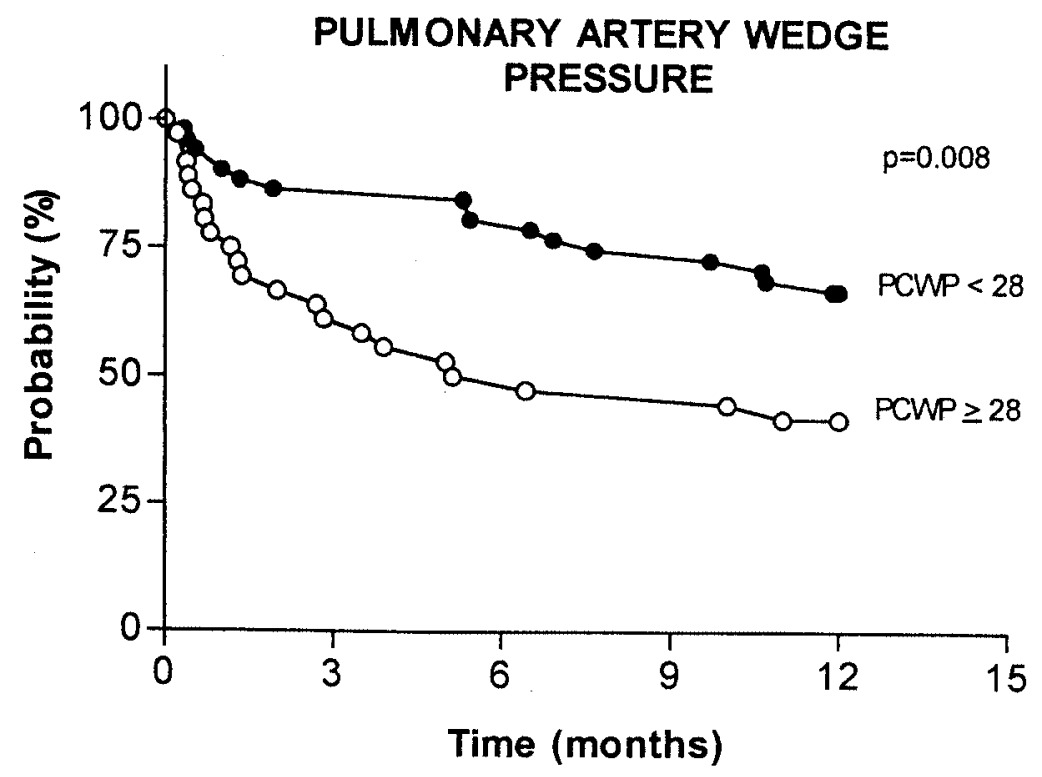

Figure 4. Actuarial survival curves according to pulmonary artery wedge pressure in $\mathrm{mm} \mathrm{Hg}$. 


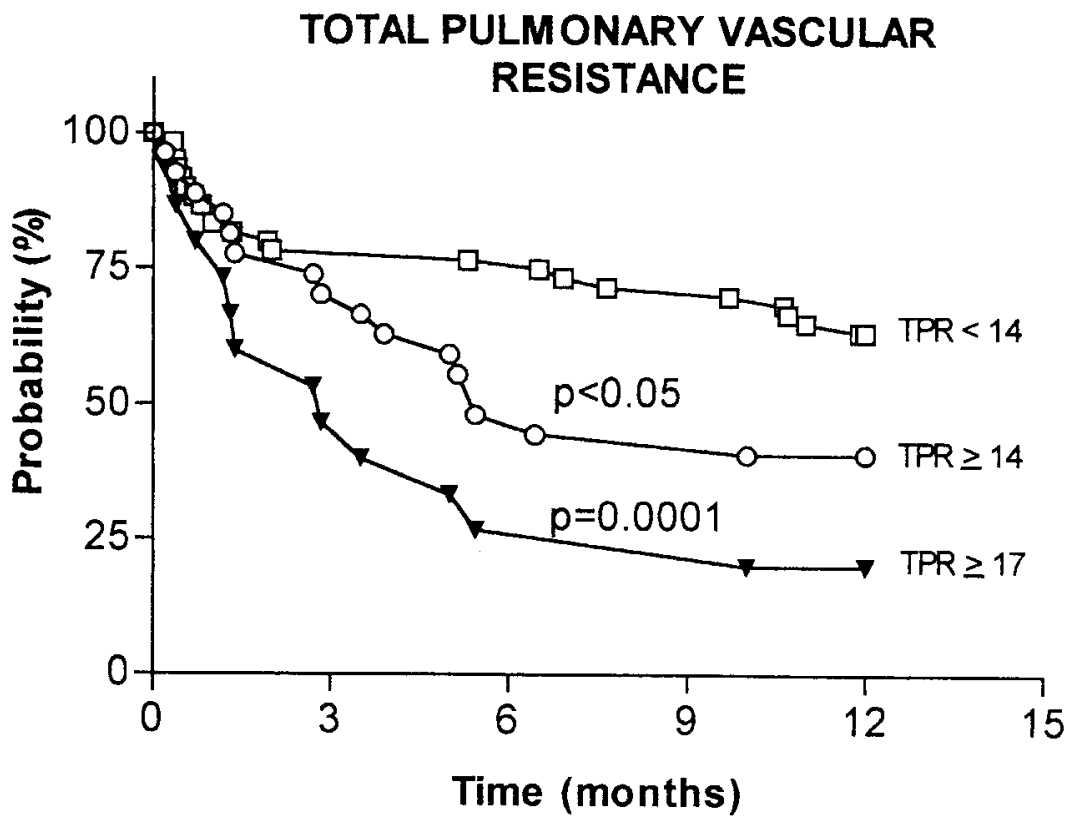

Figure 5. Actuarial survival curves according to total-pulmonary vascular resistance in Wood units.

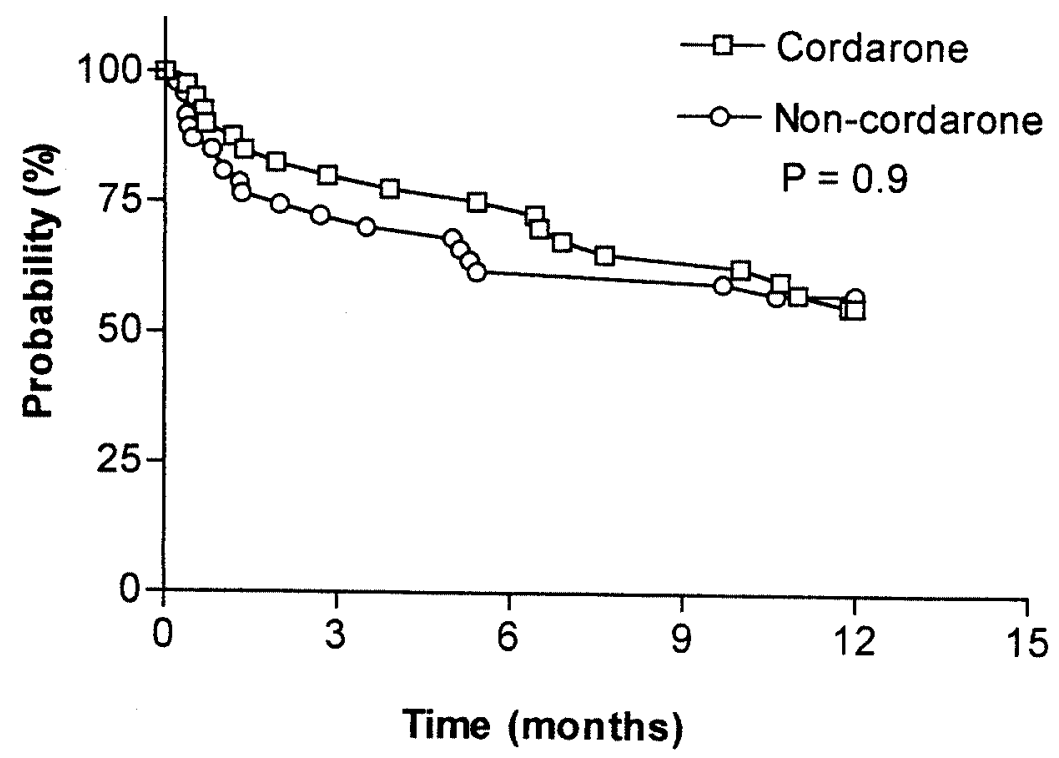

Figure 6. Kaplan-Meier survival curves in 87 patients with a left vetricular ejection fraction < $25 \%$ and subdivided groups with and without cordarone treatment at one-year after assessment. 


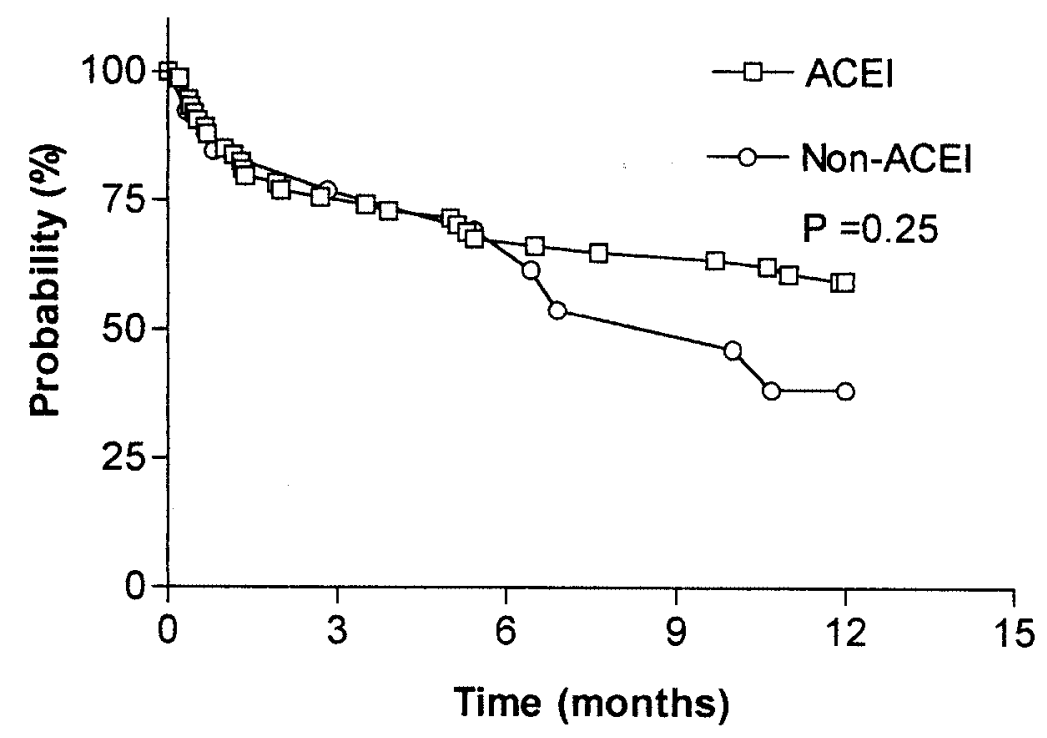

Figure 7. Kaplan-Meier survival curves in 87 patients with a left vetricular ejection fraction < $25 \%$ and subdivided groups with and without ACEls treatment at one-year after assessment.

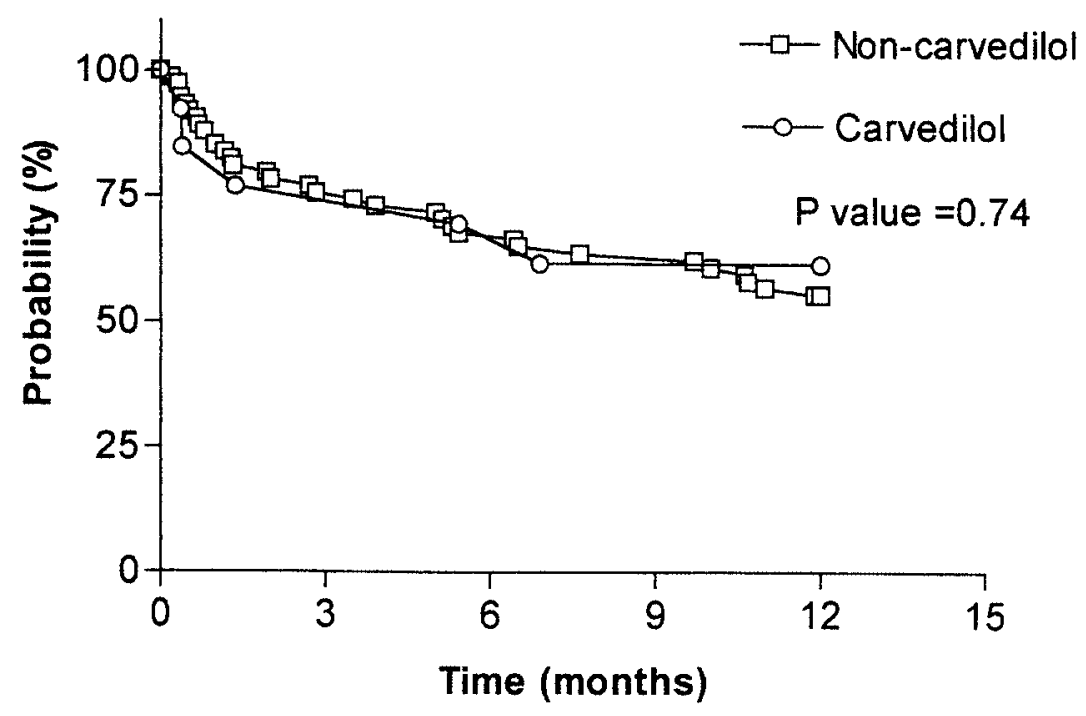

Figure 8. Kaplan-Meier survival curves in 87 patients with a left vetricular ejection fraction $<25 \%$ and subdivided groups with and without carvedilol treatment at one-year after assessment. 
PWP and TPR ( $r=0.68, p<0.0001)$, were observed in the present study. All three hemodynamic variables showed strong correlations with each other.

The 1-year survival curves were compared among the non-transplanted patients with and without cordarone, ACEIs or carvedilol treatment. The results showed no significant differences in any of the groups treated with cordarone, ACEIs and carvedilol. The results are shown in Figures 6 to 8 .

\section{DISCUSSION}

This study focused on the natural history and prognostic parameters of very severe cardiac failure in small-built Chinese patients who were referred for HT. Treatment of severe heart failure in this study was homogenous, including angiotensin converting enzyme inhibitors, diuretics, digoxin and cordarone. Our selection criteria for HT focused primarily on resting hemodynamic and echocardiographic data and clinical presentations. The severity of circulatory decompensation in this series was shown by the clinical profile, including a mean EF of $17 \%$ and functional class III to IV symptoms. The hemodynamic profile included an average initial heart rate of 94 beats $/ \mathrm{min}$, CI of $2.0 l / \mathrm{min} / \mathrm{m}^{2}$, PWP of $26 \mathrm{~mm} \mathrm{Hg}$, RAP of $13 \mathrm{~mm} \mathrm{Hg}$, and TPR of $13 \mathrm{~W}$. The $2-\mathrm{D}$ and M-mode color echocardiographic profile included an average LVEDD of $70 \mathrm{~mm}$ and LVESD of $61 \mathrm{~mm}$, and MR of 2+. VT was present in $67 \%$ of our series, which is equal to the results of the V-HeFT Study $(68 \%)$. $^{5}$ These data demonstrate that our study objectives were in severely global left ventricular dysfunction.

Correlations with mortality rates in patients with congestive heart failure are multifactorial. Based on the literatures, patients in whom left ventricular filling pressures during therapy and CI $<1.8 \mathrm{l} / \mathrm{min} / \mathrm{m}^{2}$, with an $\mathrm{EF}<20 \%$ and severe clinical compromise, PWP $>25$ to $27 \mathrm{~mm} \mathrm{Hg}$, and RAP $>10 \mathrm{~mm} \mathrm{Hg}$ have all associated with 1-year survivals of less than $40 \% .{ }^{15-18)}$ Our results were consistent with those of previous studies.

Although several studies have identified prognostic markers in patients with DCM, the discriminatory power of these classic parameters (etiology, duration of disease onset, EF, symptom classes, VT, cardiothoracic ratio, systolic blood pressure, PVR, FS) appeared to be less accurate in severely symptomatic heart failure patients who were referred for assessment and accepted for HT in our study. Therefore, it is crucial for us to improve stratification of the high-risk population for HT and other 
alternative procedures such as cardiomyoplasty or implantation of circulatory assist devices. ${ }^{19)}$

In the present study, we evaluated 119 patients with EF $<25 \%$. Twenty-six percent of the patients were found to have better resting hemodynamics after medical treatment. EF, VT, FS and LV chamber size did not differ significantly from those patients accepted for transplant. Importantly, several right cardiac hemodynamic variables showed high levels of statistical difference as compared to that of those patients accepted for transplant at similar LVEF levels. This might partly explain why variable hemodynamic predictors of mortality have been suggested in patients with heart failure and $\mathrm{EFs}<20 \%$, if the selection criteria for HT were different. $^{2,5,6,8,9,19)}$

Survival: The survival rates of the patients with a CI of more than $2.0 \mathrm{l} /$ $\min / \mathrm{m}^{2}$ and an EF less than $20 \%$ were $85 \%, 65 \%$ at 6 and 12 months, respectively. This finding was lower than the result reported by Mancini's group who reported on $83 \%$ (43 of 52) survival rate at 1 year in patients with ambulatory heart failure. ${ }^{8)}$ The survival rate of the patients with a CI of less than $2.0 \mathrm{l} / \mathrm{min} / \mathrm{m}^{2}$ and an EF less than $20 \%$ was $59 \%$ at 6 months and $52 \%$ at 1 year, a finding which is close to the results reported by Bocchi's group of a $61 \%$ survival rate at 1 year for patients with homogenous idiopathic DCM under medical treatment ${ }^{19)}$ and Mancini's group, $47 \%$ in non-homogenous transplant rejected patients due to noncardiac reasons, and higher than Stevenson's group, $21 \%$ in patients denied a transplant for nonmedical criteria. ${ }^{2)}$ Overall, our results were similar to the survival rates of patients with severe left ventricular dysfunction with very low EFs. ${ }^{2,7-9)}$

We used univariate analysis to examine the relation of all measured variables to survival. Our results suggest that only four variables (PWP, TPR, CI and inotropic agent treatment) provide valuable prognostic information for median survival among referral patients with severe heart failure at 6 and 12 months after HT assessment. The survival of patients with a CI $<1.65 \mathrm{l} / \mathrm{min} / \mathrm{m}^{2}$ was $48 \%(15$ of 31$)$ at 6 months and $42 \%$ (13 of 31) at 1 year. The survival of patients with a PWP $\geq 28 \mathrm{~mm} \mathrm{Hg}$ was $50 \%$ (18 of 36) at 6 months and $42 \%(21$ of 36) at 1 year. The survival of patients with a TPR $\geq 14 \mathrm{~W}$ was $48 \%$ (13 of 27) and $41 \%$ (11 of 27) and TPR $\geq 17 \mathrm{~W}$ was $27 \%$ (4 of 15 ) and $20 \%$ (3 of 15) at 6 months and 1 year, respectively. The latter results are similar to those of Szlachcic, et al. who described a $77 \%$ 1-year mortality rate for patients with PEOC of $10 \mathrm{ml} / \mathrm{kg} / \mathrm{min}$ or less. On the other hand, the overall survival of the patients with TPR $<14 \mathrm{~W}$ was $77 \%$ (46 of 60) at 6 months and $63 \%$ 
(38 of 60) at 1 year. In multivariate analysis, CI, and TPR were again the best independent predictors of mortality in patients with referral heart failure at 6 months and 1 year after HT assessment.

Correlation showed a strong statistical significance between the three hemodynamic predictors (CI, TPR, PWP) in the present study. CI and TPR were valuable predictors of mortality in our patients with ambulatory heart failure. These findings were different from that of previous reports. ${ }^{20,21)}$ Also, we have observed a trend of increases in arteriovenous oxygen difference and / or decreases in pulmonary arterial oxygen saturation following decreases in CI in our study. The results revealed that hemodynamic status would change at different stages in patients with progressive heart failure. We used inotropic agents to improve cardiac output and reduce the preload of our subjects with advanced heart failure. However, the survival rate seemed unfavorable for such a condition. This may indicate negative effects of neurohormones released on the preload, afterload and cardiac pumping activity during inotropic agent treatment in a subset of patients with ESCM. In addition, pulmonary arterial vasoconstriction with hypertension usually occurs after hypoxia and neurohormonal factor release to the circulatory system in patients with severe heart failure. These findings suggest that a vicious cycle may occur in such patients with presentations of progressive hemodynamic decompensation and a decrease in PEOC as well. For this subset of patients, inotropic agent treatment may result in a poor outcome in our study and other series. ${ }^{21,22)}$ Causes of death: In our study, the majority of deaths (21 of 27, $78 \%$ ) resulted from progressively hemodynamic decompensation among transplant accepted patients. Moreover, most of the transplant accepted patients (23 of $27,85 \%$ ) required HT or a ventricular assist device (VAD) within the first 6 months after initial assessment in our series. This is consistent with previous studies through different approaches. Actually, only 2 of 11 (18\%) transplant denied patients died from circulatory failure. On the other hand, sudden death was only $15 \%$ (4 of 11) among transplant accepted patients but $73 \%$ ( 8 of 11) among transplant denied patients. This is consistent with the previous findings of Stevenson's group. In a group of patients considered "too well" and in a "medically stabilized" group, these investigators noted that the incidence of sudden death was $82 \%$ and $90 \%$, respectively. Other studies consisting of candidates rejected for HT due to preserved exercise capacity (PEOC $\geq 14 \mathrm{ml} / \mathrm{kg}$ / min) and patients with lesser symptoms of heart failure reported all deaths were sudden. ${ }^{8)}$

Clinical implications: The definition of disease severity and selection cri- 
teria of recipients for HT in patients with ESCM varied from study to study. This may explain the diverse results of prognostic predictors and survival among previous trials. Furthermore, observation for 3 to 6 months after optimization of medical treatment is necessary when considering the potentially reversible causes of heart failure.

Our present study clearly illustrated the severity of hemodynamic impairment is among the most powerful predictors of mortality among symptomatic severe heart failure patients with EFs less than $<20 \%$. Our results suggest that measurement of TPR and CI provide the best prognostic information and optimal timing for HT among referral patients with severe heart failure. Therefore, serial right heart catheterization should be performed, if the patient's clinical condition deteriorates. ${ }^{23)}$

On the other hand, the major threat to survival in our patients with preserved CI was sudden death. Most of the patients with VT received amiodarone therapy in our study. However, sudden death was still unpreventable with antiarrhythmic agents in our study and is widely reported in such populations. ${ }^{2,8,24-28)}$ Until now, there is still no reliable marker with which to identify those patients at highest risk for sudden death. Further studies are necessary to assess a more accurate and safer method for the prediction of sudden death and the automatic implantable cardioverterdefibrillator would be preferable to antiarrhythmic drugs or HT in this subset of patients. This is different from prior criteria suggested by previous investigators. ${ }^{2,26}$ They observed a high mortality in patients with EFs of less than $20 \%$ and proposed that all patients with such EFs undergo HT regardless of hemodynamic parameters or symptoms.

LVEF provides information on global ventricular function that is a powerful predictor of survival in patients with heart failure due to various causes. However, the correlation between baseline EF and baseline exercise capacity was very weak in V-HeFT I and II trials. Also, patients with preserved exercise capacity tend to have lower mean pulmonary pressures. $\left.{ }^{8}, 10\right)$ This illustrated the dissociation between exercise capacity or resting hemodynamic variables and $\mathrm{EF}^{9,28)}$ Therefore, patients with very low EF may essentially be stratified to establish subgroups with different risks and prognoses in the short and long term on the basis of CI, PEOC or other methods. ${ }^{2,8,9,21,29)}$

The effect of vasodilators on prognosis remains controversial, ${ }^{30,31)}$ while ACEIs and beta-blockers have been reported to have beneficial effects on prognosis. ${ }^{6,32)}$ In the present study, ACEIs or carvedilol treatment had no favorable role in reducing mortality in patients with severe heart failure at 1 year after assessment. 
The final decision to transplant should be based on multiple factors such as clinical, hemodynamic and echocardiographic parameters. Other noninvasive methods with serial studies such as PEOC and neurohormonal factors $^{5)}$ may aid in the selection of candidates for HT and predict the prognosis of patients with severe heart failure.

Despite the limitations imposed by the design of this study (small sample number of patients who were not really randomized, and retrospective data analysis) and although some variables such as NE, tumor-necrotizing factor, endothelin-1 and plasma ANF were not examined, the results suggest that TPR and CI have powerful predictive values in patients with severe heart failure secondary to ischemic or nonischemic dilated cardiomyopathy.

\section{CONCLUSIONS}

In this study, treatment with inotropic agents had a bad outcome and ACEI or carvedilol administration did not convincingly reduce overall mortality in the short-term in our small number of patients with severe heart failure. Also, sudden death was unpreventable with amiodarone treatment in our small-built patients with severe heart failure. Because there is still no reliable predictor of sudden death in the literature and our study, it is important for us to find a safer and more accurate marker for such events in the future. Among clinical, echocardiographic and hemodynamic parameters, TPR and cardiac index were the best prognostic indicators in our series. Reevaluation with serial right heart catheterization for such a group of patients at 3 to 6 month intervals may be important. Our results clearly illustrated the 6 month and 1 year outcomes and provided important predictors for Chinese patients with severe heart failure and therefore the indication and timing of HT, or, implantation of circulatory assist devices can be reliably predicted.

\section{REFERENCES}

1. Romeo F, Pelliccia F, Cianfrocca C, et al. Determinants of end-stage idopathic dilated cardiomyopathy: a multivariate analysis of 104 patients. Clin Cardiol 1989; 12: 387-92.

2. Stevenson LW, Tillish JH, Hamilton M, Luu M, Chelimsky-Fallick C, Moriguchi J, Kabashigawa J, Walden J. Importance of hemodynamic response to therapy in predicting survival with ejection $<20 \%$ secondary to ischemic or non-ischemic dilated cardiomyopathy. Am J Cardiol 1990; 66: 1348-54.

3. Unverferth D, Baker P. Value of endomyocardial biopsy. Am J Med 1986; 80 (suppl 2B): 22-32.

4. Shirey E, Proudfit W, Hawk W. Primary myocardial disease: correlation with clinical findings, angiographic and biopsy date. Am Heart J 1980; 99: 198-207. 
5. Cohn JN, Johnson GR, Shabeai R, Loeb H, Tristani F, Rector TS, Smith R, Fletcher R. Ejection fraction, peak exercise oxygen consumption, cardiothoracic ratio, ventricular arrhythmias, and plasma norepinephrine as determinants of prognosis in heart failure. The V-HeFT VA Cooperative Studies Group. Circulation 1993; 87: VI5-16.

6. The CONSENSUS Trial Study Group. Effects of enalapril on mortality in severe congestive heart failure. Results of the Cooperative North Scandinavian Enalapril Survival Study (CONSENSUS). N Engl J Med 1987; 316: 1429-35.

7. Brophy JM, Deslauries G, Rouleau JL. Long-term prognosis of patients presenting to the emergency room with decompensated congestive heart failure. Can J Cardiol 1994; 10: 543-47.

8. Mancini DM, Eisen H, Kussmaul W, Mull R, Edmunds LH, Wilson JR. Value of peak exercise oxygen consumption for optimal timing of cardiac transplantation in ambulatory patients with heart failure. Circulation 1991; 83: 778-86.

9. Szlachcic J, Massie BM, Kramer BL, Topic N, Tubau J: Correlates and prognostic implication of exercise capacity in chronic congestive heart failure. Am J Cardiol 1985; 55: 1037-42.

10. Baker BJ, Wilen MM, Boyd CM, Dinh H, Franciosa JA: Relation of right ventricular ejection fraction to exercise capacity in chronic left ventricular failure. Am J Cardiol 1984; 54: 596-9.

11. Stevenson LW, Lacks H, Drinkwater DC, Kahan BD, Terasaki PI. Cardiac transplantation: selection, immunosuppression and survival. West J Med 1988; 149: 572-83.

12. Evans RW, Menninen DL, Garrison LP, Maier AM. Donor availability as the primary determinant of the future of heart transplantation. JAMA 1986; 255: 1892-8.

13. Huang CM, Young MS. Transradial approach for diagnosis of cardiovascular disease in Taiwanese patients: catheter selection, feasibility, complication and application. Acta Cardiol Sin 1999; 15: 9-16.

14. Hinkle LE, Thaler HT. Clinical classification of cardiac deaths. Circulation 1982; 65: 457-63.

15. Franciosa JA, Wilen M, Ziesche S, Cohn JA. Survival in men with severe chronic left ventricular failure due to either coronary heart disease or idiopathic dilated cardiomyopathy. Am J Cardiol 1983; 51: 831-6.

16. Unverfeth DV, Magorien RD, Moeschberger ML, Baker PB, Fetters JK, Leier CV. Factors influencing the oneyear mortality of dilated cardiomyopathy. Am J Cardiol 1984; 54: 147-52.

17. Likoff MJ, Chandler SL, Kay HR. Clinical determinants of mortality in chronic congestive heart failure secondary to idiopathic dilated or to ischemic cardiomyopathy. Am J Cardiol 1987; 59: 634-8.

18. Wilson JR, Schwartz JS, St. John Sutton M, Ferraro N, Horowitz, LN, Reichek N, Josephson ME. Prognosis in severe heart failure: relation to hemodynamic measurements and ventricular ectopic activity. J Am Coll Cardiol 1983; 2: 403-9.

19. Bocchi EA, Bellotti G, Moreira LF, et al. Mid-term results of heart transplantation, cardiomyopathy, and medical treatment of refractory heart failure caused by idiopathic dilated cardiomyopathy. J Heart Lung Transplant 1996; 15: 736-45.

20. Pelliccia F, d'Amati G, Cianfrocca C, Bernucci P, Nigri A, Marino B, Gallo P. Histomorphometric features predict 1-year outcome of patients with idiopathic dilated cardiomyopathy considered to be at low priority for cardiac transplantation. Am Heart J 1994; 128: 316-25.

21. Anguita M, Arzon JM, Bueno G, Latre JM, Sanchi M, Torres F, Gimenez D, Concha M, and Valles F. Clinical and hemodynamic predictors of survival in patients aged $<65$ years with severe congestive heart failure secondary to ischemic or nonischemic dilated cardiomyopathy. Am J Cardiol 1993; 72: 413-7.

22. Dies F, Krell MJ, Whitlow P, Liang C, Goldenberg I, Applefeld MM, Gilbert EM. Intermittent dobutamine in ambulatory outpatients with chronic heart failure (abstract). Circulation 1986; 74 (suppl 2, pt 2): II-38.

23. Mudge GH, Goldstein S, Addonizio LJ, Caplan A, Mancini D, Levine TB, Ritsch ME Jr, Stevenson LW. Twenty-fourth Bathesda conference: cardiac transplantation: Task Force 3: recipient guidelines/priorization. J Am Coll Cardiol. 1993; 22: 22-31.

24. Lampert S, Lown B, Graboys T, Podrid P, Blatt C. Determinants of survival in patients with malignant ventricular arrhythmia associated with coronary artery disease. Am J Cardiol 1988; 61: 791-7.

25. Grayboys T, Lown B, Podrid P, DeSilva R. Long-term survival of patients with malignant ventricular arrhythmia treated with antiarrhythmic drugs. Am J Cardiol 1982; 50: 437-43.

26. Keogh AM, Baron DW, Hickie JB. Prognostic guides in patients with idiopathic or ischemic cardiomyopathy assessed for heart transplantation. Am J Cardiol 1990; 65: 903-8. 
27. Clelend J, Dargie H, Ford I, Mortality in heart failure: clinical variables of prognostic value. Br Heart J 1987; 58: $572-82$.

28. Wyse DG, Morganroth J, Hallstrom A. Analysis of early ventricular proarrhythmia in the Cardiac Arrhythmia Suppression Trial (CAST) (abstract). J Am Coll Cardiol 1992; 19: 77A.

29. Pinamonti B, Di Lenarda A, Sinagra G, Camerini F. Restrictive left ventricular filling pattern in dilated cardiomyopathy: Clinical, echocardiographic and hemodynamic correlations and prognostic implications. J Am Coll Cardiol 1993; 22: 808-15.

30. Cohn JN, Archibald DGA, Ziesche S, et al. Effect of vasodilator therapy on mortality in chronic congestive heart failure. N Engl J Med 1986; 314: 1547-52.

31. Furberg CD, Yusuf S. Effect of vasodilators on survival in chronic congestive heart failure. Am J Cardiol 1985; 55: 1110-2.

32. The SOLVD investigators. Effect of enalapril on mortality and the development of heart failure in asymptomatic patients with left ventricular ejection fractions. N Engl J Med 1992; 327: 685-91. 